\title{
Review of Emotion Recognition in Mild Cognitive Impairment
}

\author{
Donna McCade ${ }^{a, b}$ Greg Savage ${ }^{b}$ Sharon L. Naismith ${ }^{a}$ \\ ${ }^{a}$ Ageing Brain Centre, Brain and Mind Research Institute, University of Sydney, and bepartment of Psychology \\ and ARC Centre of Excellence in Cognition and its Disorders, Macquarie University, Sydney, N.S.W., Australia
}

\section{Key Words}

Emotion recognition $\cdot$ Emotion processing $\cdot$ Facial

expressions $\cdot$ Social cognition $\cdot$ Mild cognitive impairment

\begin{abstract}
Background: While dysfunction in emotion recognition is sometimes apparent with aging, and is frequently evident in Alzheimer's disease, it is unclear whether individuals who have a high risk of developing dementia exhibit demonstrable changes. Method: A review of the literature pertaining to mild cognitive impairment was undertaken to discern the extent to which emotion recognition deficits are evident in this prodromal period. Results: A search of Medline, Psycinfo and Psyextra databases using specific key words identified only six relevant studies. These studies suggest that the ability to accurately identify facial expressions of affect is compromised. Conclusions: Research in this area is in its infancy. Suggestions are made for furthering our knowledge about this important ability which affects interpersonal relationships, daily functioning, mental well-being and quality of life.

Copyright $\odot 2012$ S. Karger AG, Basel
\end{abstract}

\section{Introduction}

Research interest in dementia has predominantly focused on the cognitive deficits associated with disease onset and progression, but there is growing awareness of how dementia influences the processing of emotional stimuli (e.g. recognising and comprehending facial emotional expressions). The neurobiological substrates of emotion recognition include the amygdala and superior temporal sulcus/gyrus $[1,2]$, as well as fusiform gyri, somatosensory, medial prefrontal and cingulate areas [3, 4]. The ability to accurately perceive emotional cues is thought to have evolved in primates to facilitate successful interaction in everyday social life [5]. Consequently, impaired emotion recognition can have a devastating impact on social behavioural competence [6] and is associated with increased levels of depression [7], inappropriate social behaviour [8], interpersonal problems and psychobehavioural disturbances, all of which are commonly observed in dementia $[9,10]$.

For the carers of patients with dementia, psychological and behavioural disturbances are associated with an increase in burden, psychological distress [11], and diminished quality of life [12]. For the patient, these disturbances also increase the risk of institutionalisation [11]. Hence, given the significant impact and considerable individual and societal costs, the early diagnosis of emotion recognition disturbances is important to enable the implementation of appropriate interventions. In this regard, the opportunity for early detection and secondary prevention may lie within the mild cognitive impairment (MCI) population.

The syndrome of MCI is widely used to identify individuals at risk of developing dementia. Clinical research has been predominantly informed by the amnestic MCI

\section{KARGER \\ Fax +4161306 1234 E-Mail karger@karger.ch} www.karger.com

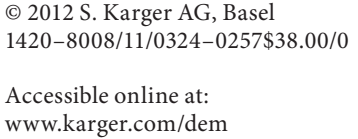

Associate Prof. Sharon Naismith

Ageing Brain Centre, Brain and Mind Research Institute

94 Mallett Street

Camperdown, NSW 2050 (Australia)

Tel. +61 29351 0781,E-Mail sharon.naismith@sydney.edu.au 
(aMCI) subtype, characterised by memory impairment which is subjectively recognised by the self or by others and objectively identified on neuropsychological testing, in the context of intact basic activities of daily living [13, 14]. Individuals with MCI may present with impairments in either single or multiple cognitive domains [15]. The most common progression from aMCI is to Alzheimer's disease $(\mathrm{AD})$, with conversion rates reported to be between 10 and 15\% per annum [13,16, 17]. The non-amnestic MCI subtype (naMCI) is associated with more diverse cognitive deficits across non-memory domains such as language, executive functioning, processing speed and visuospatial skills [15]. While further longitudinal studies are required for this subtype, conversion from naMCI may involve non-Alzheimer-like conditions such as frontotemporal dementia (FTD), vascular dementia, and dementia with Lewy bodies [18]. Psychological symptoms, including depression, anxiety and apathy, are commonly associated with both aMCI and naMCI subtypes [19]. It is important to note that whilst progression to dementia is elevated for MCI individuals, some may remain stable over time [20] and up to $28 \%$ have been estimated to return to normalcy [21,22].

The aim of this paper is to review the MCI literature pertaining to emotion recognition. As a backdrop to this focus, an initial review of emotion recognition is outlined, including the profiles associated with both normal aging and the neurodegenerative conditions of $\mathrm{AD}$ and FTD. A comprehensive review of the literature pertaining to MCI is then presented in order to ascertain whether early changes in the ability to recognise facial expressions of emotion are evident in MCI samples.

\section{What Happens to Emotion Recognition with Age?}

There is strong support for an age-related decline in emotion recognition. Studies have shown that emotion recognition performance improves from childhood through adolescence and early adulthood, but declines in later adulthood [23]. Older adults are worse than younger adults in recognising some basic emotions, a finding which holds across a range of modalities including faces, voices, bodily contexts and face-voice matching (for a review, see Ruffman et al. [24]). The recognition of angry, sad and fearful faces [25-28] is consistently shown to be problematic for older adults, in the context of relatively preserved recognition of disgust [29] and happiness [30]. Indeed some evidence suggests that the identification of disgust improves with age [25], whilst general face recognition remains relatively intact [31].
Age-related changes within distinct neural systems, particularly in temporal, limbic and/or prefrontal areas [32-34], may underlie emotion recognition difficulties, independent of general cognitive decline $[28,35]$. An alternative account for the emotion-specific effects observed in aging implicates motivational factors. Older adults are thought to prioritise emotion-regulatory goals aimed at minimising negative affect (for a review, see Carstensen and Mikels [36]), and it has been hypothesised that a tendency to preferentially process material with positive valence [37] results in the selective sparing of positive emotions observed in recognition tasks [38].

Deficits in emotion recognition observed in older adults have been attributed to age-related structural [3941] and functional changes in brain regions, such as the amygdala, orbitofrontal cortex and superior temporal areas [42], key areas involved in emotion recognition.

\section{Emotion Recognition and Dementia}

Research to date suggests that within samples of patients with dementia, deficits in emotion recognition extend beyond those attributed to normal aging. The conditions most explored are AD and FTD.

\section{Alzheimer's Disease}

Whilst emotional expression is thought to be largely intact in $\mathrm{AD}$ [43], deficits in the ability of $\mathrm{AD}$ patients to comprehend the emotional state of others using facial expressions have been observed when $\mathrm{AD}$ patients are compared with age-matched healthy controls ([44]; for a review, see McLellan et al. [45]). Results across studies vary in terms of individual emotions thought to be impaired, such as happiness [46-48], sadness [46-49], surprise [46, 49], disgust [49], fear [46-48], and anger [46-48, 50]. Neurodegeneration associated with AD is hypothesised to underlie affect processing deficits, in particular in medial temporal lobe structures [48]. In support of this, one longitudinal study reported that emotion recognition worsened with disease progression [51].

Other studies, however, have attributed observed decreases in emotion recognition to general cognitive, linguistic or visuospatial dysfunction rather than to specific emotional processing deficits [52-56]. Whilst some studies have failed to find any significant emotion processing impairment in $\mathrm{AD}$ patients, compared with healthy controls, these studies have had either small sample sizes (i.e., $\mathrm{n}=9$ [57]; $\mathrm{n}=12$ [58]), mild AD severity samples (i.e., mean Mini-Mental State Examination [MMSE] score of 24.8 [57]), or they have employed emotion identification tasks which were insufficiently sensi- 
tive to detect group differences [59]. Overall, studies to date have been characterised by methodological variability in terms of sample size, patient disease severity (e.g. encompassing very mild $\mathrm{AD}$ to moderate levels of $\mathrm{AD}$ ), participant age (e.g. ranging from 70 to 90 years) and inconsistencies in study response formats and stimuli used.

\section{Frontotemporal Dementia}

FTD encompasses a heterogeneous group of dementias associated with degeneration of the frontal or temporal brain regions. FTD produces a distinct profile of symptoms including loss of insight, social disinhibition, diminished emotions and selfishness [60-62], often with little initial cognitive decline [63]. Given the prominent role that behavioural and emotional changes play in FTD patients, it is not surprising that a number of studies have been undertaken to explore emotion recognition in this disease group, and empirical evidence strongly suggests an impaired ability to recognise a range of emotional facial expressions. Deficits have been identified in the detection of happiness [63-65]; surprise [51, 65, 66]; sadness $[56,57,63-65,67]$; disgust $[51,56,57,65,68]$; fear $[57,64,65,67]$, and anger [51, 56, 57, 63-68], when compared with healthy controls. There is some support for the finding that the recognition of negative valence emotions (sadness, fear, anger) is more severely impaired than the recognition of positive valence emotions (happiness) [67]. Impaired emotion recognition amongst FTD patients has consistently been reported across studies, despite small sample sizes used (i.e., $\mathrm{n}=6$ ) [57, 63], variability in patient MMSE scores (i.e., mean MMSE score $=22.9$ in Rosen et al. [64]; mean MMSE score $=28$ in Lough et al. [68]), differences in disease severity (e.g. encompassing mild to moderate levels of FTD), and stimuli used (e.g. static photographs and video clips). Although the precise pathophysiology of these deficits is not well understood, there is certainly considerable evidence demonstrating abnormalities in frontotemporal neural networks. Eslinger et al. [69] found right hemisphere cortical atrophy in the orbitofrontal, superior temporal, visual association and posterior cingulate, regions implicated in the mediation of emotion recognition. These findings were reinforced in a subsequent meta-analysis by Schroeter et al. [70].

To summarise, strong support exists for specific emotion recognition deficits in FTD patients, demonstrating impairments in the subjective experience of emotion and difficulty accessing the mental states of others, which seems to be independent of general cognitive impairment. In contrast, while there is evidence that emotion recognition is impaired in $\mathrm{AD}$, it is not clear whether this is a primary impairment, or whether it reflects impaired cognition generally.

\section{Method}

The literature providing a basis for this review was obtained by searching the Medline, Psycinfo and Psycextra databases for English language articles containing the key terms 'mild cognitive impairment' and 'MCI'. Other terms entered into the search were 'dementia', 'facial emotion recognition', 'face processing', 'emotion processing', 'emotion', 'social cognition' and 'social perception'. No restrictions were placed on year, with all articles up until February 2011 included. Relevant papers from the reference lists of identified papers were also reviewed. Given the focus on MCI, only studies with samples of people with age-associated cognitive impairment were included. Also, only studies which included the diagnostic criteria used to identify MCI cases [13], supported by neuropsychological testing to aid diagnosis, were reviewed. Studies with only cognitively normal individuals or that focused solely on psychiatric conditions were excluded. Only studies in which a key research focus was emotion processing were included. One study was excluded because the patient group did not differentiate between individuals with dementia and those with MCI [71]. A further study was excluded [72] due to sample size limitations (i.e., $\mathrm{n}=1$ ). Ultimately, only six studies relating to emotion recognition were eligible for inclusion in the present review (table 1).

\section{Results}

\section{Participant Characteristics and Diagnostic Criteria}

In the six studies reviewed, mean participant age ranged from 71.2 years [48] to 79.4 years [73]. Whilst not uniformly reported, the mean level of education of MCI participants varied considerably across studies, ranging from 9.8 years [74] to 18.2 years [73]. Sample size also varied from 9 MCI single-domain participants [73] to 50 aMCI participants [48].

Inconsistencies were found in diagnostic criteria used to identify MCI participants across studies. In the majority of studies, diagnoses of MCI were made according to features defined in the early proposal by Petersen et al. [13]; these included Bediou et al. [50], Fuije et al. [75], Spoletini et al. [48], and Teng et al. [73]. Accordingly, individuals with memory deficits in the context of intact general cognitive functioning (i.e., aMCI) were the primary population sampled. A minority of studies encompassed a more heterogeneous view of MCI, in line with the modified criteria of Petersen et al. [14] including aMCI participants with deficits across multiple cognitive domains [74]. 


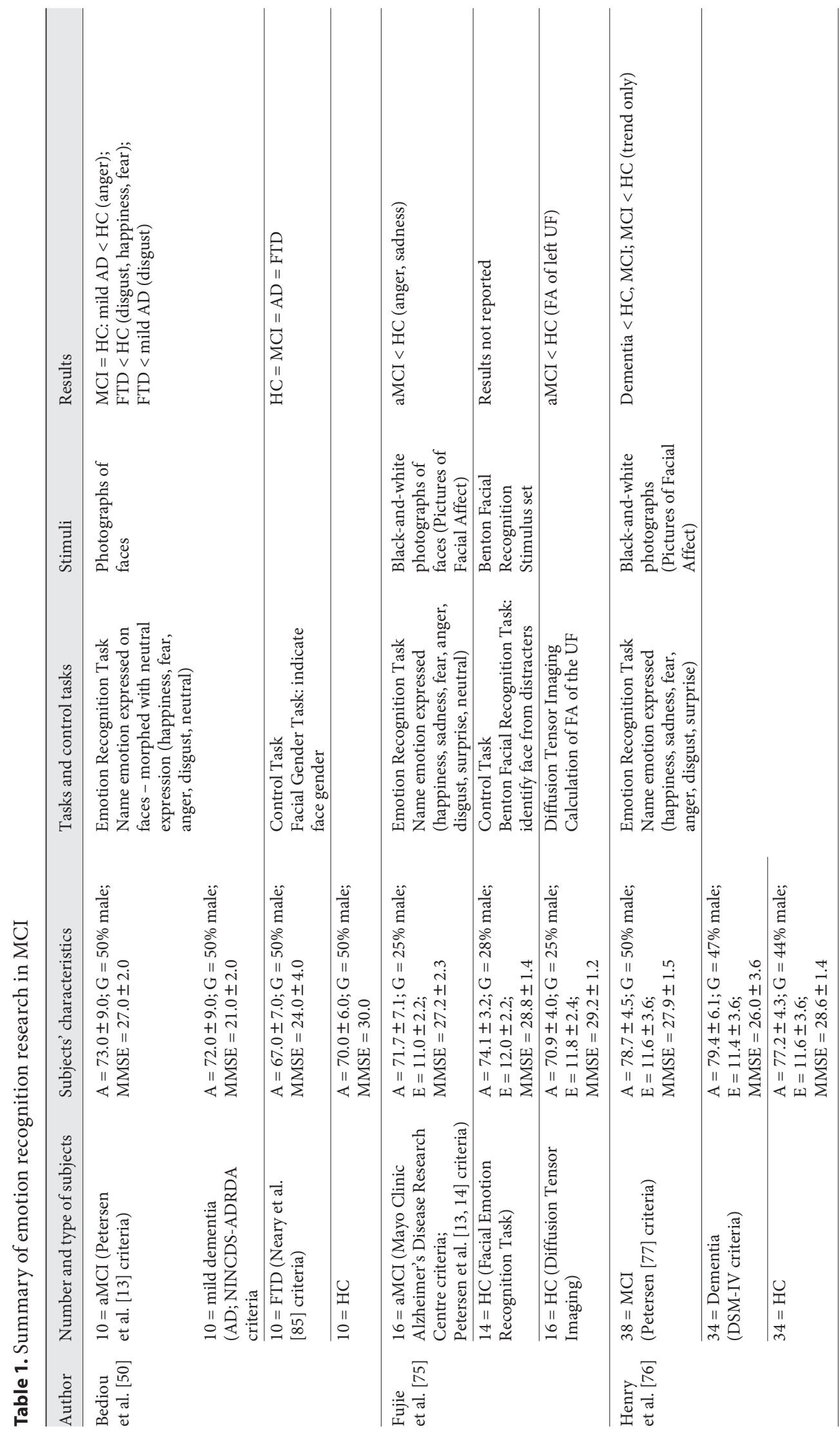




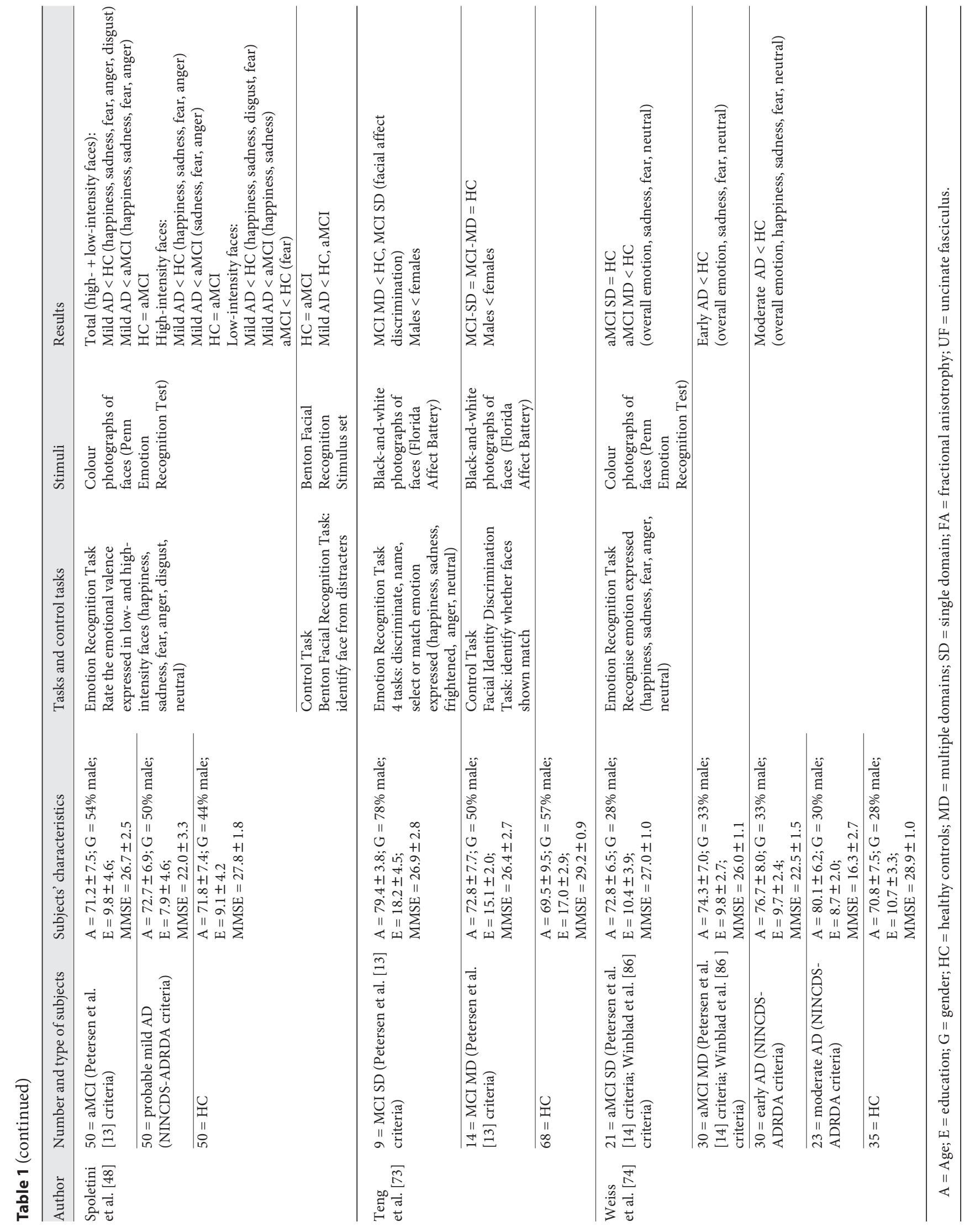


Another study [76] did not report a differentiation of MCI subtypes amongst the sample, despite using the modified Petersen [77] MCI criteria. Hence it is unclear if the sample included both amnestic and non-amnestic MCI subtypes, and also whether participants presented with deficits in single or in multiple domains. Where disclosed, the level of cognitive impairment was defined by a performance of at least 1.5 standard deviations below either age-adjusted norms $[73,74,76]$ or a general normative sample [75]. Performance was generally assessed by results on neuropsychological testing. In all studies, the MMSE was a key part of neuropsychological evaluation. In two studies, MMSE scores of greater than or equal to 23 [48] and 24 [75] were required for inclusion in the study.

Neuropsychological testing undertaken generally covered memory, language and executive functioning. However, some studies provided more extensive testing of participants, including visuospatial/constructional ability $[48,73,74]$ and attention/processing speed [73]. Neuropsychological performance data on cognitive testing were reported for each participant group in four studies $[48,50,73,75]$. Other studies only partially reported neuropsychological comparison data, most often MMSE scores.

Exclusion criteria reported were generally consistent between studies, excluding participants with disorders known to impact upon cognitive status (e.g. neurological disorders; major medical illnesses) and also emotion processing (e.g. psychiatric disorders; visual acuity). Some studies adopted more stringent strategies $[48,73,75]$, excluding participants based on additional factors such as drug dependence, as well as lesions or abnormalities observed using magnetic resonance imaging. All studies recruited healthy controls as a comparison group. Most control samples were matched demographically with MCI participants; however, sample differences were reported across groups for age and education [73].

\section{Emotion Recognition Measures}

All studies adopted a cross-sectional design to assess facial emotion processing. Facial affect recognition tests were used in all studies, whereby participants were required to identify which emotion best accounted for the expression displayed on a photographed face. One study additionally used an emotion discrimination task, in which participants determined whether the expressed emotions on a pair of photographed faces were the same or different, as well as emotion matching and selection tasks, where the participant was required to match the target emotions presented either verbally or visually with a set of photographed faces [73].

One study also incorporated neuroimaging in an effort to relate emotion recognition to neural integrity [75]. Specifically, the authors used diffusion tensor imaging to calculate the fractional anisotropy of the uncinate fasciculus, a white matter tract connecting the anterior part of the temporal lobe with the orbital and polar frontal cortex, areas which are postulated to contribute to the interaction between cognition and emotion [78]. This in turn was correlated with individual performance on an emotion recognition task.

\section{Stimuli Employed}

Stimuli used in emotion recognition tasks were typically static photographs of faces. Standardised and validated instruments have chiefly been used, predominantly from the Ekman and Friesen [79] 'Pictures of Facial Affect' series $[75,76]$ or the Penn Emotion Recognition Test $[48,74]$. Studies have varied in the use of either black-andwhite $[75,76]$ or colour facial photographs $[48,74]$; all have used stimuli with deliberate, posed facial expressions.

In regard to emotions examined, happiness, anger and fear were examined in all studies. The emotions least explored were surprise and disgust. Two studies incorporated emotional stimuli differing in intensity $[48,50]$, one of which morphed emotional stimuli with neutral expressions [50].

\section{Task Format}

Most studies used self-paced, unlimited exposure to stimuli material; however, Bediou et al. [50] placed time restrictions (e.g. $1 \mathrm{~s}$ ) on stimuli presentation, potentially increasing working memory demands and presenting a more cognitively difficult exercise. Response formats for tasks were predominantly forced choice, and no studies placed time limits on participant responses. Tasks placed demands on participants not only in regard to their social cognitive skills but also drew on abilities from other cognitive domains. For example, semantic analysis is required to comprehend response options.

\section{Control Tasks}

The inclusion of tasks to control for perceptual face processing deficits in emotion recognition tasks was noted in four studies. Either an identity discrimination task, in which participants indicated whether photographs of people were the same or different $[48,73,75]$, or gender identification tasks, in which the participant was required to label the gender of presented faces [50], were used. 


\section{Synthesis of Findings}

All of the six identified studies investigated the ability of MCI cases to recognise emotional expressions. Two studies found no significant difference in performance relative to healthy controls: one including aMCI cases specifically [50], with only a small effect size (Cohen's $d=0.37$ ), and one including MCI cases defined generally [76], although the latter study did find a trend towards impairment in MCI cases ( $\mathrm{p}=0.062)$ and a moderate effect size (Cohen's $d=0.59$ ). It is noteworthy that these studies either included MCI participants with the mildest degree of global cognitive impairment with a mean MMSE score of 27.9 [76], or a small sample size of only 10 participants [50].

Four studies reported MCI patients to be significantly worse than healthy controls at recognising facial expressions of emotions [48, 73-75], with effect sizes ranging from moderate (Cohen's $d=0.51$ [48]) to large (Cohen's $d=1.01$ [75]; Cohen's $d=1.36$ [74]). Interestingly, two of these studies included MCI comparison groups with either single or multiple cognitive domains impaired [73, 74], but impairment was significant only for those groups with cognitive deficits across multiple domains. Subsequent analyses in Teng et al. [73] revealed that in the context of similar MMSE scores, the MCI multiple-domain group had a greater degree of overall cognitive impairment than the MCI single-domain group. Whilst no significant relationship was found to exist between the breadth of cognitive impairments and performance on an emotion discrimination task, performance on neuropsychological tests of executive functioning was reported as the best predictor of emotion discrimination ability within the MCI multiple-domain group.

Emotion-specific deficits were reported in three studies. Diminished ability was reported amongst MCI participants in recognising sad [74,75], fearful [48, 74], angry [75] and neutral [74] faces. Whilst no emotion-specific deficit was found in Teng et al. [73], MCI multiple-domain cases found happy faces were significantly easier to recognise than sad, angry and fearful faces, and neutral faces were significantly easier to recognise than sad faces.

An effect for emotion intensity was reported by Spoletini et al. [48]. In this study, impaired performance within aMCI participants was found only for low-intensity stimuli, specifically for fearful faces; this finding was attributed to fearful expressions being more subtle and hence more difficult to recognise. This is consistent with findings reported in Bediou et al. [50], in which the performances of aMCI cases resembled those of mild $\mathrm{AD}$ patients when emotional expression was more subtle (e.g.
$40 \%$ intensity). However, in the latter study, as mentioned above, overall results did not achieve significance.

In terms of other affective biases, depressed individuals have been found to be less accurate in recognising facial affect and to demonstrate a negative bias when interpreting emotional expressions [80]. Only a small number of studies assessed patient depressive symptoms using either the Geriatric Depression Scale $[73,74]$ or the Beck Depression Inventory [50]. One study controlled for the potential effect of depressive symptoms on emotion recognition. Weiss et al. [74] found that whilst depression was associated with poorer accuracy in emotion recognition, depression did not significantly account for task performance.

Different studies have proposed a variety of factors to account for findings of impaired emotion recognition in MCI. Specific regional pathology includes degeneration of corticolimbic systems, particularly involving the temporal [48] and frontal lobes (e.g. orbitofrontal regions [73]) as suggested by performance on specific neuropsychological tests. One study used imaging to correlate white matter pathology with emotion recognition [75]. Specifically, aMCI individuals were found to have significantly reduced fractional anisotropy measurements of the left uncinate fasciculus when compared with healthy controls. Within the aMCI group, a significant positive relationship was shown to exist between fractional anisotropy values of the left uncinate fasciculus and accuracy in recognising surprise and fear. The authors concluded that uncinate fasciculus pathology may play either a direct or intervening role in impaired emotion processing, in association with amygdalar or hippocampal pathology. Importantly, in three studies the inclusion of control tasks enabled face processing deficits to be specifically excluded as factors explaining impaired emotion recognition $[48,73,75]$.

Emotion processing deficits were hypothesised to have a practical consequence for the non-verbal communication, interpersonal relatedness, and quality of life in MCI cases [48]. However, this remains speculative as the reallife social functioning and well-being of individuals with MCI was not explored in any of these studies.

\section{Discussion}

Although research in emotion recognition in $\mathrm{MCI}$ is clearly in its infancy, this review synthesises evidence derived from six studies to date, and suggests that this aspect of social perception is indeed compromised. The un- 
derlying aetiology of this decrement, however, is not yet clear. Overall, the majority of the six studies reviewed do report worse facial emotion recognition in MCI cases over and above those associated with normal aging. Furthermore, these deficits appear to occur in the context of intact facial information processing. Although no consistent emotion-specific impairment is reported, there is some evidence to suggest that the detection of negative emotions is selectively affected (e.g. anger, fear, and sadness). Whilst this may reflect the overrepresentation of negative emotions included in studies, in that of the seven different emotions tested in studies only two (i.e., happiness and surprise) could be regarded as positive emotions, results are consistent with findings in both normal aging and dementia. There is also some limited evidence to suggest that more pervasive neuropsychological impairment (i.e., demonstrated by impairments across multiple cognitive domains) is associated with greater decline in emotion recognition.

Considerable caution must be exercised in drawing any firm conclusions, given the variability in findings within the limited research undertaken to date, as well as inconsistencies in the methodological approaches taken. For example, studies differed in the type of stimuli used, emotional expressions investigated, and in the difficulty of tasks undertaken by study participants. Furthermore, a number of questions remain unanswered. Critically, does the reported decline in emotion recognition represent subtle changes in other wise normal performance? In addition, how does diminished accuracy in emotion recognition relate to everyday social functioning, including interpersonal relationships, quality of life, neuropsychiatric symptoms such as depression and anxiety, and caregiver burden?

It is possible that poor performance on emotion recognition tasks reflects the cognitive decline associated with MCI rather than impaired emotion processing, per se. The role played by overall cognitive impairment in negatively influencing emotion recognition has previously been reported within an AD sample [52], in which patients performed poorly due to difficulties comprehending and/or remembering task instructions. Indeed, individuals found to be most impaired in emotion recognition in one study showed greater overall cognitive decline [73]. However, a more thorough analysis of the impact of cognition on emotion recognition is difficult due to differences across studies in the application of diagnostic criteria employed. In the majority of studies, a broad diagnosis of aMCI or MCI was employed to classify cases. This approach does not differentiate the extent of cogni- tive decline amongst participants (e.g. single or multiple cognitive domains). Further, some studies undertook only limited neuropsychological testing across a narrow range of cognitive domains.

Nevertheless, the possibility still exists that changes in emotion recognition are indicative of early signs of impaired emotion processing. Support for this may be found in neuroimaging studies of MCI individuals demonstrating atrophy in regions implicated in emotion processing, including the amygdala, fusiform gyrus [81], superior temporal gyrus, insula [82] and anterior cingulate [83]. However, only one study to date has correlated emotion recognition results with neuroimaging data [75].

To clarify the aetiology underpinning emotion recognition deficits, future studies should seek to address the limitations evident in current research. Adopting the most recent MCI diagnostic criteria [15] to classify more precisely MCI cases according to subtypes (e.g. single or multiple domains) will help to clarify any specific emotion recognition profiles in an essentially heterogeneous patient population. Given its relative recency as a specific subtype of interest, no study has included an naMCI sample. The association of the naMCI single-domain subtype with FTD [18], a disease with the most compelling evidence to date of an emotion recognition deficit, strongly suggests that investigation of this subtype is warranted. Similarly, those with prominent frontal-subcortical changes, as often seen in vascular dementia, warrant investigation since data have linked pathology in this circuitry with early changes in emotion recognition.

Methodological considerations include addressing sample size issues, ensuring uniform matching of patient and control group demographics, and controlling for the potential confounds of facial processing and visuospatial deficits. The effects of depression or anxiety, known to be prevalent in MCI and to impact detrimentally on emotion processing, must be accounted for.

Future research should aim to explore how changes in emotion recognition affect 'real-life' interpersonal behaviour and social functioning in MCI. The reports of significant others represent an important source of information in this regard. Such research would subsequently inform whether early intervention to address emerging behavioural issues would benefit an MCI population [84]. Ultimately, longitudinal research will be required to determine the association of emotion recognition with neurodegeneration, and specifically, whether changes in emotion recognition predict clinical diagnosis and functional outcome. 


\section{References}

-1 Adolphs R, Tranel D, Damasio H, Damasio A: Impaired recognition of emotion in facial expressions following bilateral damage to the human amygdala. Nature 1994;372:669-672.

-2 Sato T, Bottlender R, Schroter A, Möller H-J: Psychopathology of early-onset versus lateonset schizophrenia revisited: an observation of 473 neuroleptic-naive patients before and after first-admission treatments. Schizophr Res 2004;67:175-183.

$\checkmark 3$ Adolphs R: The neurobiology of social cognition. Curr Opin Neurobiol 2001;11:231-239.

4 Craik FIM, Moroz TM, Moscovitch M, Stuss DT, Wincour G, Tulving E, Kapur S: In search of the self: a positron emission tomography study. Psychol Sci 1999;10:26-34.

5 Brüne $\mathrm{M}$, Brüne-Cohrs U: Theory of mind - evolution, ontogeny, brain mechanisms and psychopathology. Neurosci Biobehav Rev 2006;30:437-455.

-6 Mueser KT, Doonan R, Penn DL, Blanchard JJ, Bellack AS, Nishith P, DeLeon J: Emotion recognition and social competence in chronic schizophrenia. J Abnorm Psychol 1996; 105:271-275

7 Carton JS, Kessler EA, Pape CL: Nonverbal decoding skills and relationship well-being in adults. J Nonverbal Behav 1999;23:91-100.

$>8$ Spell LA, Frank E: Recognition of nonverbal communication of affect following traumatic brain injury. J Nonverbal Behav 2000;24: 285-300.

-9 Chiu MJ, Chen TF, Yip PK, Hua MS, Tang LY: Behavioral and psychologic symptoms in different types of dementia. J Formos Med Assoc 2006; 105:556-562.

-10 Shimokawa A, Yatomi N, Anamizu S, Torii S, Isono H, Sugai Y, Kohno M: Influence of deteriorating ability of emotional comprehension on interpersonal behavior in Alzheimertype dementia. Brain Cogn 2001;47:423-433.

$\checkmark 11$ Brodaty H: Care-givers and behavioral disturbances: effects and interventions. Int Psychogeriatr 1996;8:455-458.

-12 Shin L-S, Carter M, Masterman D, Fairbanks L, Cummings JL: Neuropsychiatric symptoms and quality of life in Alzheimer disease. Am J Geriatr Psychiatry 2005;13:469-474.

$\checkmark 13$ Petersen RC, Smith GE, Waring SC, Ivnik RJ, Tangalos EG, Kokmen E: Mild cognitive impairment clinical characterization and outcome. Arch Neurol 1999;56:303-308.

14 Petersen RC, Doody R, Kurz A, Mohs RC, Morris JC, Rabins PV, Ritchie K, Rossor M, Thal L, Winblad B: Current concepts in mild cognitive impairment. Arch Neurol 2001;58: 1985-1992.

-15 Petersen RC: Mild cognitive impairment as a diagnostic entity. J Intern Med 2004;256: 183-194.

$\checkmark 16$ Rountree SD, Waring SC, Chan WC, Lupo PJ, Darby EJ, Doody RS: Importance of subtle amnestic and nonamnestic deficits in mild cognitive impairment: prognosis and conversion to dementia. Dement Geriatr Cogn Disord 2007;24:476-482.
17 Fisk JD, Merry HR, Rockwood K: Variations in case definition affect prevalence but not outcomes of mild cognitive impairment Neurology 2003;61:1179-1184.

18 Petersen RC, Morris JC: Mild cognitive impairment as a clinical entity and treatment target. Arch Neurol 2005;62:1160-1163.

19 Apostolova LG, Cummings JL: Neuropsychiatric manifestations in mild cognitive impairment: a systematic review of the literature. Dement Geriatr Cogn Disord 2008;25:115-126.

20 Gauthier S, Reisberg B, Zaudig M, Petersen RC, Ritchie K, Broich K, Belleville S, Brodaty $\mathrm{H}$, Bennett D, Chertkow H, Cummings JL, de Leon M, Feldman H, Ganguli M, Hampel $\mathrm{H}$, Scheltens P, Tierney MC, Whitehouse P, Winblad B: Mild cognitive impairment. Lancet 2006;367:1262-1270.

21 Ganguli M, Dodge HH, Shen C, DeKosky ST: Mild cognitive impairment, amnestic type an epidemiologic study. Neurology 2004;63 115-121

22 Loewenstein DA, Acevedo A, Agron J, Duara R: Stability of neurocognitive impairment in different subtypes of mild cognitive impairment. Dement Geriatr Cogn Disord 2007;23: 82-86.

23 Williams LM, Mathersul D, Palmer, DM, Gur RC, Gur RE, Gordon E: Explicit identification and implicit recognition of facial emotions. 1. Age effects in males and females across 10 decades. J Clin Exp Neuropsychol 2008;31:257-277.

24 Ruffman T, Henry JD, Livingstone V, Phillips LH: A meta-analytic review of emotion recognition and aging: implications for neuropsychological models of aging. Neurosci Biobehav Rev 2008;32:863-881.

25 Calder A, Keane J, Manley T, Sprengelmeyer R, Scott S, Nimmo-Smith I, Young A: Facial expression recognition across the adult life span. Neuropsychologia 2003;41:195-202.

26 Malatesta C, Izard CE, Culver C, Nicolich M: Emotion communication skills in young, middle-aged and older women. Psychol Aging 1987;2:193-203.

-27 McDowell CL, Harrison DW, Demaree HA: Is right hemisphere decline in the perception of emotion a function of aging? Int J Neurosci 1994;79:1-11.

28 Sullivan S, Ruffman T: Social understanding: how does it fare with advancing years? Br J Psychol 2004;95:1-18.

29 Suzuki A, Hoshino T, Shigemasu K, Kawamura M: Decline or improvement? Age-related differences in facial expression recognition. Biol Psychol 2007;74:75-84.

30 MacPherson SE, Phillips LH, Della Sala S: Age, executive function, and social decision making: a dorsolateral prefrontal theory of cognitive aging. Psychol Aging 2002;17:598-609.

31 Silver H, Goodman C, Bilker W: Age in highfunctioning healthy men is associated with nonlinear decline in some 'executive' functions in late middle age. Dement Geriatr Cogn Disord 2009;27:292-300.
32 Adolphs R, Tranel D: Amygdala damage impairs emotion recognition from scenes only when they contain facial expressions. Neuropsychologia 2003;41:1281-1289.

33 Bartzokis G, Beckson M, Po H, Lu MA, Neuchterlein KH, Edwards N, Mintz J: Agerelated changes in frontal and temporal lobe volumes in men. Arch Gen Psychiatry 2001; 58:461-465.

34 Raz N, Lindenberger U, Rodrigue KM, Kennedy KM, Head D, Williamson A, Dahle C, Gerstorf D, Acker JD: Regional brain changes in aging healthy adults: general trends, individual differences and modifiers. Cereb Cortex 2005;15:1676-1689.

-35 Keightley ML, Winocur G, Burianova H, Hongwanishkul D, Grady CL: Age effects on social cognition: faces tell a different story. Psychol Aging 2006;21:558-572.

36 Carstensen LL, Mikels JA: At the intersection of emotion and cognition: aging and the positivity effect. Curr Dir Psychol Sci 2005; 14:117-121.

37 Isaacowitz DM, Wadlinger HA, Goren D, Wilson HR: Selective preference in visual fixation away from negative images in old age? An eyetracking study. Psychol Aging 2006;21:40-48.

38 Isaacowitz DM, Löckenhoff CE, Lane RD, Wright R, Sechrest L, Riedel R, Costa PT: Age differences in recognition of emotion in lexical stimuli and facial expressions. Psychol Aging 2007;22:147-159.

39 Jack CR, Petersen RC, Xu YC, Waring SC, Obrien PC, Tangalos EG, Smith GE, Ivnik RJ, Kokmen E: Medial temporal atrophy on MRI in normal aging and very mild Alzheimer's disease. Neurology 1997;49:786-794.

40 Sowell ER, Peterson BS, Thompson PM, Welcome SE, Henkenius AL, Toga AW: Mapping cortical change across the human life span. Nat Neurosci 2003;6:309-315.

41 Raz N, Rodrigue KM: Differential aging of the brain: patterns, cognitive correlates and modifiers. Neurosci Biobehav Rev 2006;30:730748.

42 Gunning-Dixon FM, Gur RC, Perkins AC, Schroeder L, Turner T, Turetsky BI, Chan RM, Loughead JW, Alsop DC, Maldjian J, Gur RE: Age-related differences in brain activation during emotional face processing. Neurobiol Aging 2003;24:285-295.

43 Magai C, Cohen C, Gomberg D, Malatesta C, Culver C: Emotion expression in mid-to latestage dementia. Int Psychogeriatr 1996;8: 383-396.

44 Shimokawa A, Yatomi N, Anamizu S, Ashikari I, Kohno M, Maki Y, Torii S, Isono H, Sugai Y, Koyami N, Matsuno Y: Comprehension of emotions: comparison between $\mathrm{Alz}$ heimer type and vascular type dementias. Dement Geriatr Cogn Disord 2000;11:268-274.

45 McLellan T, Johnston L, Dalrymple-Alford J, Porter J: The recognition of facial expressions of emotion in Alzheimer's disease: a review of findings. Acta Neuropsychiatr 2008; 20:236-250. 
46 Henry JD, Ruffman T, McDonald S, Peek O'Leary M-A, Phillips LH, Brodaty H, Rendell PG: Recognition of disgust is selectively preserved in Alzheimer's disease. Neuropsychologia 2008;46:1363-1370.

-47 Kohler C, Anselmo-Gallagher G, Bilker W, Karlawish J, Gur RE, Clark CM: Emotiondiscrimination deficits in mild Alzheimer disease. Am J Geriatr Psychiatry 2005;13: 926-933.

-48 Spoletini I, Marra C, Di Iulio F, Gianni W, Sancesario G, Giubilei F, Trequattrini A, Bria P, Caltagirone C, Spalletta G: Facial emotion recognition deficit in amnestic mild cognitive impairment and Alzheimer disease. Am J Geriatr Psychiatry 2008;16:389-398.

49 Hargrave R, Maddock RJ, Stone V: Impaired recognition of facial expressions of emotion in Alzheimer's disease. J Neuropsychiatry Clin Neurosci 2002; 14:64-71.

-50 Bediou B, Ryff I, Mercier B, Milliery M, Hénaff M-A, D’Amato T, Bonnefoy M, Vighetto A, Krolak-Salmon P: Impaired social cognition in mild Alzheimer disease. J Geriatr Psychiatry Neurol 2009;22:130-140.

-51 Lavenu I, Pasquier F: Perception of emotion on faces in frontotemporal dementia and Alzheimer's disease: a longitudinal study. Dement Geriatr Cogn Disord 2005;19:37-41.

52 Cadieux NL, Greve KW: Emotion processing in Alzheimer's disease. J Int Neuropsychol Soc 1997;3:411-419.

53 Albert MS, Cohen C, Koff E: Perception of affect in patients with dementia of the Alzheimer type. Arch Neurol 1991;48:791-795.

54 Roudier M, Marcie P, Grancher AS, Tzortzis C, Starkstein S, Boller F: Discrimination of facial identity and of emotions in Alzheimer's disease. J Neurol Sci 1998;154:151-158.

-55 Burnham H, Hogervorst E: Recognition of facial expressions of emotion by patients with dementia of the Alzheimer type. Dement Geriatr Cogn Disord 2004;18:75-79.

-56 Lavenu I, Pasquier F, Lebert F, Petit H, Van der Linden M: Perception of emotion in frontotemporal dementia and Alzheimer disease. Alzheimer Dis Assoc Disord 1999;13:96101.

57 Fernandez-Duque D, Black SE: Impaired recognition of negative facial emotions in patients with frontotemporal dementia. Neuropsychologia 2005;43:1673-1687.

58 Bucks RS, Radford SA: Emotion processing in Alzheimer's disease. Aging Ment Health 2004;8:222-232.

59 Ogrocki PK, Hills AC, Strauss ME: Visual exploration of facial emotion by healthy older adults and patients with Alzheimer disease. Neuropsychiatry Neuropsychol Behav Neurol 2000;13:271-278.

60 Bozeat S, Gregory CA, Ralph MA, Hodges JR: Which neuropsychiatric and behavioural features distinguish frontal and temporal variants of frontotemporal dementia from Alzheimer's disease? J Neurol Neurosurg Psychiatry 2000;69:178-186.
61 Bathgate D, Snowden JS, Varma A, Blackshaw A, Neary D: Behaviour in frontotemporal dementia, Alzheimer's disease and vascular dementia. Acta Neurol Scand 2001;103:367-378.

62 Mourik JC, Rosso SM, Niermeijer MF, Duivernvoorden $\mathrm{HJ}$, van Swieten JC, Tibben A: Frontotemporal dementia: behavioural symptoms and care-giver distress. Dement Geriatr Cogn Disord 2004;18:299-306.

63 Keane J, Calder AJ, Hodges JR, Young AW: Face and emotion processing in frontal variant frontotemporal dementia. Neuropsychologia 2002;40:655-665.

64 Rosen HJ, Pace-Savitsky K, Perry RJ, Kramer JH, Miller BL, Levenson RW: Recognition of emotion in the frontal and temporal variants of frontotemporal dementia. Dement Geriatr Cogn Disord 2004;17:277-281.

65 Diehl-Schmid J, Pohl C, Ruprecht C, Wagenpfeil S, Foerstl H, Kurz A: The Ekman 60 Faces Test as a diagnostic instrument in frontotemporal dementia. Arch Clin Neuropsychol 2007;22:459-464.

-66 Kessels RPC, Gerritsena L, Montagne B, Ackl N, Diehl J, Danek A: Recognition of facial expressions of different emotional intensities in patients with frontotemporal lobar degeneration. Behav Neurol 2007;18:31-36.

67 Rosen HJ, Perry RJ, Murphy J, Kramer JH, Mychack P, Schuff N, Weiner M, Levenson RW, Miller BL: Emotion comprehension in the temporal variant of frontotemporal dementia. Brain 2002;125:2286-2295.

68 Lough S, Kipps CM, Treise C, Watson P, Blair JR, Hodges JR: Social reasoning, emotion and empathy in frontotemporal dementia. Neuropsychologia 2006;44:950-958.

69 Eslinger PJ, Moore P, Troiani V, Antani S, Cross K, Kwok S, Grossman M: Oops! Resolving social dilemmas in frontotemporal dementia. J Neurol Neurosurg Psychiatry 2007;78:457-460.

70 Schroeter ML, Raczka K, Neumann J, von Cramon Y: Neural networks in frontotemporal dementia - a meta-analysis. Neurobiol Aging 2008;29:418-426.

71 Washburn AM, Sands LP: Social cognition in nursing home residents with and without cognitive impairment. J Gerontol B Psychol Sci 2006;61B:174-179.

72 Modinos G, Obiols JE, Pousa E, Vicens J: Theory of mind in different dementia profiles. J Neuropsychiatry Clin Neurosci 2009; 21:100-101.

73 Teng E, Lu PH, Cummings JL: Deficits in facial emotion processing in mild cognitive impairment. Dement Geriatr Cogn Disord 2007;23:271-279.

74 Weiss EM, Kohler CG, Vonbank J, Stadelmann A, Kemmler G, Hinterbuber H, Hinterbuber H, Marksteiner J: Impairment in emotion recognition abilities in patients with mild cognitive impairment, early and moderate Alzheimer disease compared with healthy comparison subjects. Am J Geriatr Psychiatry 2008;16:974-980.
75 Fujie S, Namiki C, Nishi H, Yamada M, Miyata J, Sakata D, Sawamoto N, Fukuyama H, Hayashi T, Murai T: The role of the uncinated fasciculus in memory and emotional recognition in amnestic mild cognitive impairment. Dement Geriatr Cogn Disord 2008;26: 432-439.

76 Henry JD, Thompson C, Ruffman T, Leslie F, Withall A, Sachdev P, Brodaty H: Threat perception in mild cognitive impairment and early dementia. J Gerontol B Psychol Sci 2009;64B:603-607.

77 Petersen RC: Mild cognitive impairment: current research and clinical implications. Semin Neurol 2007;27:22-31.

78 Barbas H: Connections underlying the synthesis of cognition, memory, and emotion in primate prefrontal cortices. Brain Res Bull 2000;52:319-330.

79 Ekman P, Friesen WV: Pictures of Facial Affect. Palo Alto, Consulting Psychologists Press, 1976.

$>80$ Leppänen JM: Emotional information processing in mood disorders: a review of behavioral and neuroimaging findings. Curr Opin Psychiatry 2006;19:34-39.

$>81$ Whitwell JL, Przybelski SA, Weigand SD, Knopman DS, Bradley DS, Boeve SF, Petersen RC, Jack CR Jr: 3D maps from multiple MRI illustrate changing atrophy patterns as subjects progress from mild cognitive impairment to Alzheimer's disease. Brain 2007; 130:1777-1786.

82 Karas GB, Scheltens P, Rombouts SA, Visser PJ, van Schijndel RA, Fox NC: Global and local gray matter loss in mild cognitive impairment and Alzheimer's disease. Neuroimage 2004;23:708-716

83 Chételat G, Desgranges B, De La Sayette V, Viader F, Eustache F, Baron JC: Mapping gray matter loss with voxel-based morphometry in mild cognitive impairment. Neuroreport 2002;13:1939-1943.

84 Naismith SL, Glozier N, Burke D, Carter PE, Scott E, Hickie IB: Early intervention for cognitive decline: is there a role for multiple medical or behavioural interventions? Early Interv Psychiatry 2009;3:19-27.

85 Neary D, Snowden JS, Gustafson L, Passant U, Stuss D, Black S, Freedman M, Kertesz A, Robert PH, Albert M, Boone K, Miller BL, Cummings J, Benson DF: Frontotemporal lobar degeneration: a consensus on clinical diagnostic criteria. Neurology 1998;51:15461554.

86 Winblad B, Palmer K, Kivipelto M, Jelic V, Fratiglioni L, Wahlund LO, Nordberg A, Bäckman L, Albert M, Almkvist O, Arai H, Basun H, Blennow K, De Leon M, Decarli C, Erkinjuntti T, Giacobini E, Graff C, Hardy J, Jack C, Jorm A, Ritchie K, Van Duijn C, Visser P, Petersen RC: Mild cognitive impairment - beyond controversies, towards a consensus: report of the International Working Group on Mild Cognitive Impairment. J Intern Med 2004;256:240-246. 